\title{
Growth phase-dependent transcription of emrKY, a homolog of multidrug efflux emrAB genes of Escherichia coli, is induced by tetracycline
}

\author{
Hiroyuki Tanabe, Katsuhide Yamasaki, Motoki Furue, Kanehisa Yamamoto, Akinori Katoh, \\ Mayu Yamamoto, Sachiko Yoshioka, Hideaki Tagami, ${ }^{1}$ Hiroji Aiba, ${ }^{1}$ and Ryutaro Utsumi ${ }^{\star}$ \\ Department of Agricultural Chemistry, Faculty of Agriculture, Kinki University, 3327-204, Nakamachi, Nara 631, Japan \\ ${ }^{1}$ Department of Molecular Biology, Faculty of Science, Nagoya University, Nagoya 464-01, Japan
}

(Received July 4, 1997; Accepted September 25, 1997)

\begin{abstract}
The genes emrK and emrY were found between genes dsdA and evgA at $51 \mathrm{~min}$ on the Escherichia coli chromosome and form an operon. EmrK and EmrY are 50.4 and $63.3 \%$ identical in amino acid sequences to EmrA and EmrB, respectively, which together make up a multidrug resistant pump. To show that the emrKY operon can be expressed, we cloned the promoter with pMC1403 and constructed an emrK-lacZ' protein fusion plasmid, pMKD1. In E. coli MC4100 containing pMKD1, its expression was increased in the presence of a subinhibitory concentration of tetracycline, chloramphenicol or salicylate, but not by carbonylcyanide $m$-chlorophenylhydrazone, nalidixic acid or kanamycin. Furthermore, we have shown that emrKY transcription dependent on the growth phase is actually induced by tetracycline using a $\mathbf{S 1}$ nuclease protection assay.
\end{abstract}

Key Words_efflux pump; Escherichia coli; multidrug resistance; tetracycline

Drug-resistant strains of bacteria are an increasing threat to human health. The mechanism of drug resistance involves enzymatic degradation and other modification of drugs, alteration of the drug target, or the transport of certain classes of drugs out of the cell (Davies, 1994). Some bacteria have pumps that can actively transport various compounds; the pumps are called multidrug-resistant (MDR) pumps. MDR pumps are found in a variety of bacterial species, and their presence in pathogens such as Staphylococcus aureus and Pseudomonas aeruginosa poses a threat to public health. Their presence in Escherichia coli and other (generally) nonpathogenic bacteria contributes to intrinsic (background) resistance to antimicrobials (George, 1996; Lewis, 1994; Nikaido, 1996; Paulsen et al., 1996).

Many genes coding for MDR pumps have been mapped on E. coli chromosomal DNA (Paulsen et al., 1996), but except for acrA, acrB, emrA, and emrB, their gene expressions are not known in detail.

Recently we newly found emrK and emrY genes (Utsumi et al., 1996) which resembled emrA and emrB

\footnotetext{
* Address reprint requests to: Dr. Ryutaro Utsumi, Department of Agricultural Chemistry, Faculty of Agriculture, Kinki University, 3327-204, Nakamachi, Nara 631, Japan.
}

(Lomovskaya and Lewis, 1992), respectively, but we did not know if they are actually expressed. In this study, we show that their expression, dependent on the growth phase, is induced by tetracycline.

\section{Materials and Methods}

Bacterial strains, plasmids and growth media. E. coli strains and plasmids used in this study are listed in Table 1. All E. coli strains were grown at $37^{\circ} \mathrm{C}$ in $\mathrm{L}$ broth containing $10 \mathrm{~g}$ of polypeptone, $5 \mathrm{~g}$ of yeast extract, and $5 \mathrm{~g}$ of $\mathrm{NaCl}$ per liter.

Nucleotide sequencing and analysis. 16B9 DNA (a Kohara library), prepared as previously described (Kohara et al., 1987), was digested with Pstl. The 12$\mathrm{kb}$ fragment that contained the genes evgA and evgS was extracted from the gel with a Prep-A-Gene DNA purification system (Bio-Rad Laboratories, Inc., Hercules), cloned into the Pstl site of pUC19 and named pKT06. We analyzed 3.2-kb of the upstream region of evgA using a DNA autosequencer (ABI Co., Foster City, model 373A) with Dye Deoxy Terminator cycle sequencing. The open reading frames (ORFs) were found with software from Genetyx Mac (SDC Co., Ltd., Tokyo, Japan). A search for similarity was done in the databases of GenBank and SwissPROT by 
Table 1. Bacterial strains and plasmids.

\begin{tabular}{|c|c|c|}
\hline Strain or plasmid & Relevant characteristics & Source or reference \\
\hline \multicolumn{3}{|l|}{ Strains } \\
\hline MC4100 & $\mathrm{F}^{-}$araD139 $\Delta($ argF-lac)U169rpsL150relA1fib5301deoC1ptsF25rbsR & Shihavy et al., 1984 \\
\hline GC4468 & $\mathrm{F}^{-}$lacU169rpsL & Greenberg et al., 1991 \\
\hline JHC1069 & GC1069 marR(cfxB1)zdd2207::Tn10km & Greenberg et al., 1991 \\
\hline $\mathrm{JHC1096}$ & GC4468 $\Delta($ marRAB $) 1738 z e e-239:: \operatorname{Tn} 9 \mathrm{~cm}^{r}$ & Greenberg et al., 1991 \\
\hline \multicolumn{3}{|l|}{ Plasmids } \\
\hline pSK001 & $\begin{array}{l}\text { 5.6-kb HindlII fragment containing evgA and evgS genes; } \\
\text { N-terminal portion of emrK was cloned into pUC19 }\end{array}$ & Utsumi et al., 1994 \\
\hline pKT06 & $\begin{array}{l}\text { 12-kb Pst fragment containing emrK, emrY, evgA, } \\
\text { and evgS genes, cloned into pUC19 }\end{array}$ & This study \\
\hline pKT03 & $\begin{array}{l}F k b l \text { fragment }(5.1-\mathrm{kb}) \text { containing evgA and evgS was } \\
\text { removed from pKT06 and ligated by itself }\end{array}$ & This study \\
\hline pMC1403 & For constructing protein fusion to $l a c Z^{\prime}$ & Casadaban et al., 1980 \\
\hline pMKD1 & pMC1403 derivative, emrK-lac $Z^{\prime}$ protein fusion, $\mathrm{Ap}^{r}$ & This study \\
\hline
\end{tabular}

Blastmail.

Construction of the fusion plasmid. A 523-bp fragment of pSK001 (Utsumi et al., 1994) containing the predicted promoter region and the $\mathrm{N}$-terminal portion (11 amino acid residues) of EmrK was amplified by PCR with primer A, 5'-TAGAATTCTCCCTTTGCAATGAAGC-3' and primer B, 5'-CGGGATCCGTACTAATCATGTCTTC-3' (Fig. 1). After this amplified fragment was digested with both $E c o R I$ and $B a m H I$, it was ligated in frame to lac $Z^{\prime}$ of pMC1403 treated with both $E c o R I$ and BamHI and used to transform E. coli MC4100 cells, which were selected on MacConkey plates containing lactose and ampicillin. The emrKlac $Z^{\prime}$ protein fusion plasmid was named pMKD1.

$\beta$-Galactosidase assay. Stationary-phase cultures were diluted $1: 100$ and used to subculture fresh LB broth with the appropriate antibiotic(s). Culturing was done with shaking at $37^{\circ} \mathrm{C}$. Samples were taken at the times specified hereafter for the different experiments, and the $\beta$-galactosidase activity was assayed in duplicate as described by Miller (1972).

Transcriptional analysis. Cellular RNA was extracted with sodium dodecyl sulfate-phenol at $60^{\circ} \mathrm{C}$. The DNA fragment ${ }^{32} \mathrm{P}$-labeled at its $5^{\prime}$ end was hybridized to the cellular RNA, treated with $\mathrm{S} 1$ nuclease and analyzed as described elsewhere (Aiba et al., 1981). The probes used were prepared as follows: 478-bp containing emrKY promoter region was prepared from pSK001 DNA cut with Stul and Hpal. This DNA fragment was labeled with ${ }^{32} \mathrm{P}$ at its $5^{\prime}$ end according to a procedure described previously (Aiba et al., 1981). After the labeled fragment was treated with EcoRV, the 445-bp fragment was used as the probe for the $S 1$ nuclease protection assay shown in Fig. 4.

Primer C (5'-CCGGGATCCGTACTAATCATGTCTTC$\left.3^{\prime}\right)$, primer D (5'-TAGAATTCTCCCTTTGCAATGAAGC-3') and pSK001 were used for PCR. PCR amplification was performed in a Perkin Elmer DNA Thermal
Cycler and used an initial step $\left(95^{\circ} \mathrm{C}\right.$ for $5 \mathrm{~min}, 50^{\circ} \mathrm{C}$ for $5 \mathrm{~min}, 75^{\circ} \mathrm{C}$ for $5 \mathrm{~min}$ ), followed by 29 cycles at $95^{\circ} \mathrm{C}$ for $1 \mathrm{~min}, 50^{\circ} \mathrm{C}$ for $1 \mathrm{~min}$, and $75^{\circ} \mathrm{C}$ for $3 \mathrm{~min}$. The PCR product was cut with BamHI and EcoRI. This DNA fragment was labeled with ${ }^{32} \mathrm{P}$ at its $5^{\prime}$ end according to a procedure described previously (Aiba et al., 1981). This labeled fragment was used as the probe for the $\mathrm{S} 1$ nuclease protection assay shown in Fig. 5.

\section{Results and Discussion}

\section{Sequences of emrKY}

Sequences 3.2-kb long on both strands containing the emrK and emrY of pKT06 were determined. Two open reading frames were found: ORF1, with 351 amino acids (MW 38,362) and ORF2 with 512 amino acids (MW 56,000). ORF1 and ORF2 had optimum scores of 949 and 1094, and were 50.45 and $63.3 \%$ identical to the multidrug efflux pump components EmrA and EmrB, respectively. They were between the $d s d A$ and $\operatorname{evg} A$ genes at $51 \mathrm{~min}$ on the E. coli chromosome and constituted an operon. ORF1 and ORF2 were named emrK and emrY, respectively, and deposited as Accession No. D78108 (Utsumi et al., 1996).

\section{Effects of drugs on emrK-lac $Z^{\prime}$ expression}

To find if emrKY can be expressed, we cloned their promoter with $\mathrm{pMC} 1403$ to construct emrK-lac Z' protein fusion plasmid, pMKD1 (Fig. 1). In E. coli MC4100 containing pMKD1, its expression was investigated. It was increased after $24 \mathrm{~h}$ incubation in the presence of a subinhibitory concentration of tetracycline, chloramphenicol or salicylate, while carbonylcyanide $m$ chlorophenylhydrazone (CCCP), nalidixic acid, kanamycin and ethanol (4\%) had no effect (Fig. 2).

emrAB was expressed in the presence of CCCP 


\section{Organization at $51 \mathrm{~min}$ region of the chromosomal DNA}
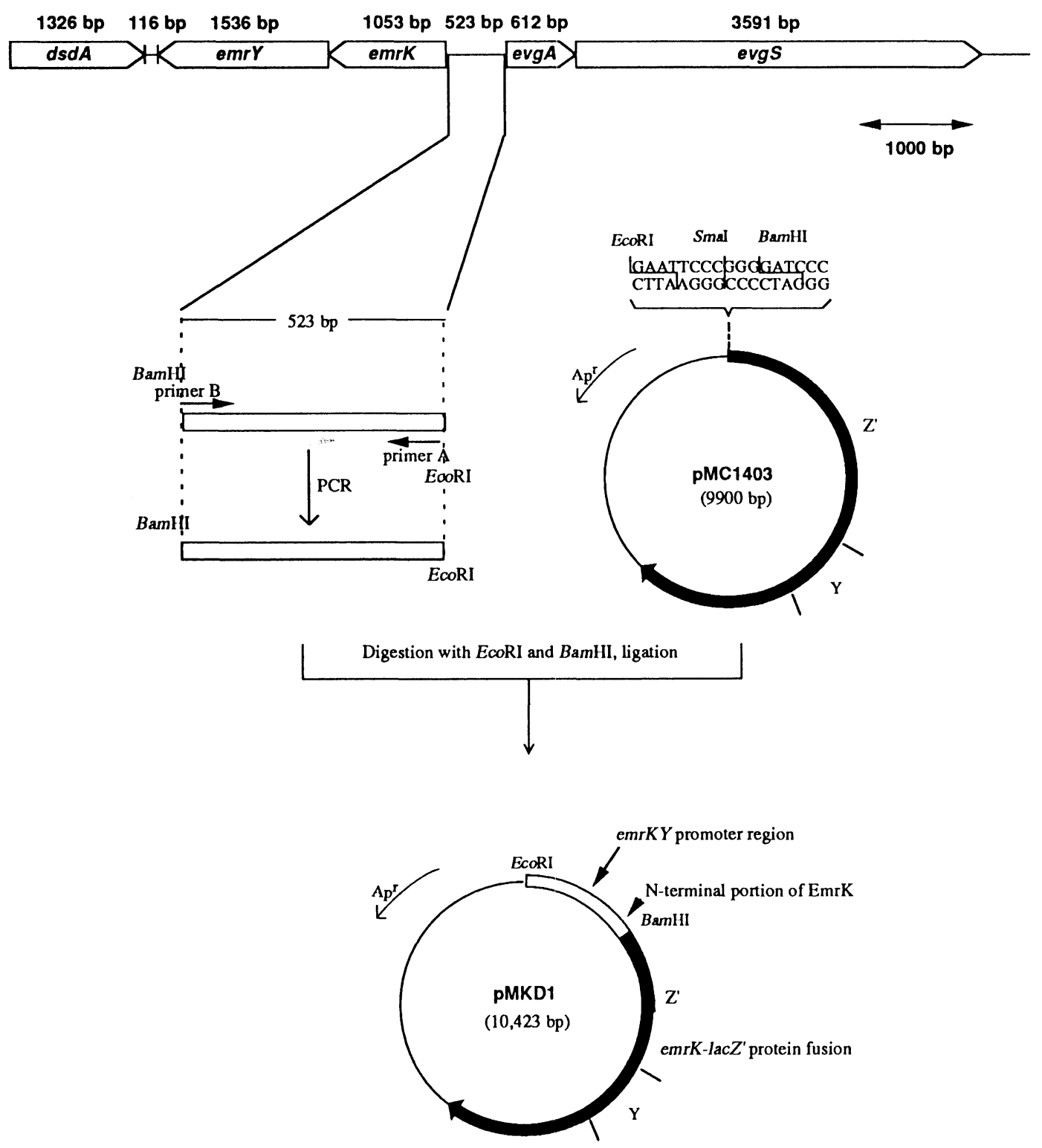

Fig. 1. Construction of pMKD1.

The nucleotide sequences of primer A and primer B are described in the text.

and nalidixic acid (Lomovskaya et al., 1995). The transcription of acrAB was increased under general stress conditions (i.e., $4 \%$ ethanol and the stationary phase) (Ma et al., 1995). In this study, we showed that emrKlac $Z^{\prime}$ expression was increased after long incubation in the presence of tetracycline, chloramphenicol or salicylate.

These results also suggest that tetracycline is the most effective drug to induce the emrKY operon and the tetracycline-dependent promoter of emrKY is located between the emrKY and evgAS operons.
Growth phase-dependent induction of emrKY by tetracycline

emrK-lac $Z^{\prime}$ expression was investigated for $24 \mathrm{~h}$ in the presence or absence of tetracycline $(2 \mu \mathrm{M})$. It was obviously induced at $24 \mathrm{~h}$ in the presence of a subinhibitory concentration of tetracycline (Fig. 3).

Furthermore, we have shown, using $S 1$ nuclease protection assays, that the emrKY transcript was actually induced at $16 \mathrm{~h}$ when E. coli MC4100 containing pMKD1 was cultured in the presence of a subinhibitory concentration $(2 \mu \mathrm{M})$ of tetracycline (Fig. 4A). To investigate the effect of a subinhibitory concentra- 


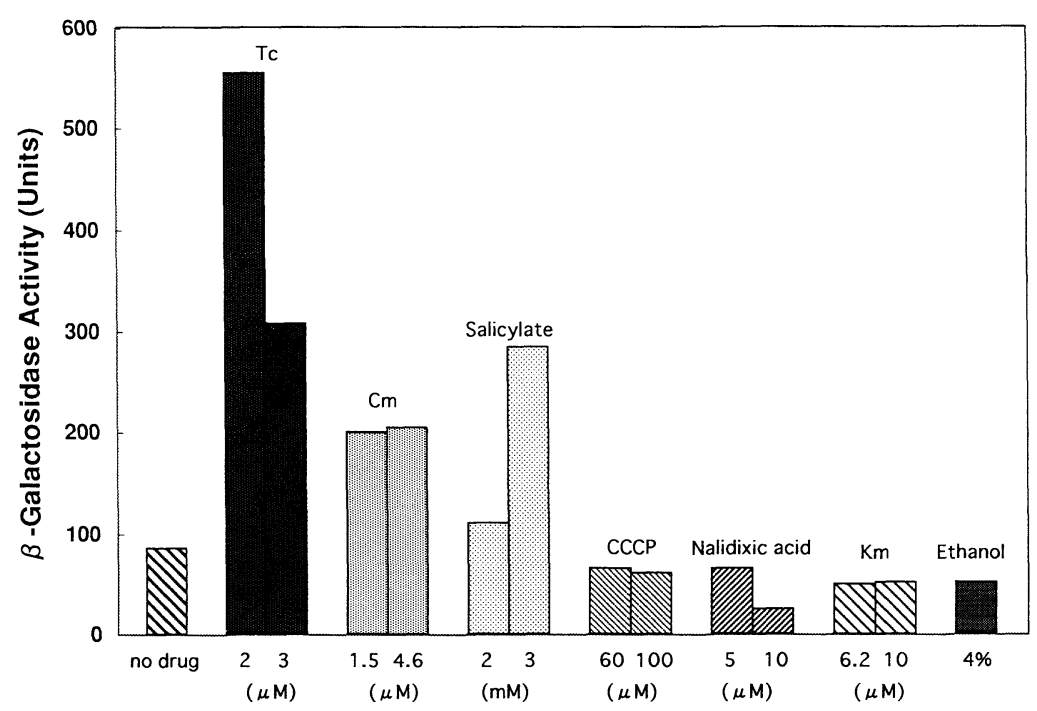

Fig. 2. Effects of drugs on emrK-lacZ' expression.

E. coli MC4100 containing PMKD1 was cultured for $24 \mathrm{~h}$ in the presence or absence of drugs as described in MATERIALS AND METHODS, and then $\beta$-galactosidase activity was assayed. Tc, tetracycline; $\mathrm{Cm}$, chloramphenicol; $\mathrm{CCCP}$, carbonylcyanide $m$ chlorophenylhydrazone; $\mathrm{Km}$, kanamycin.

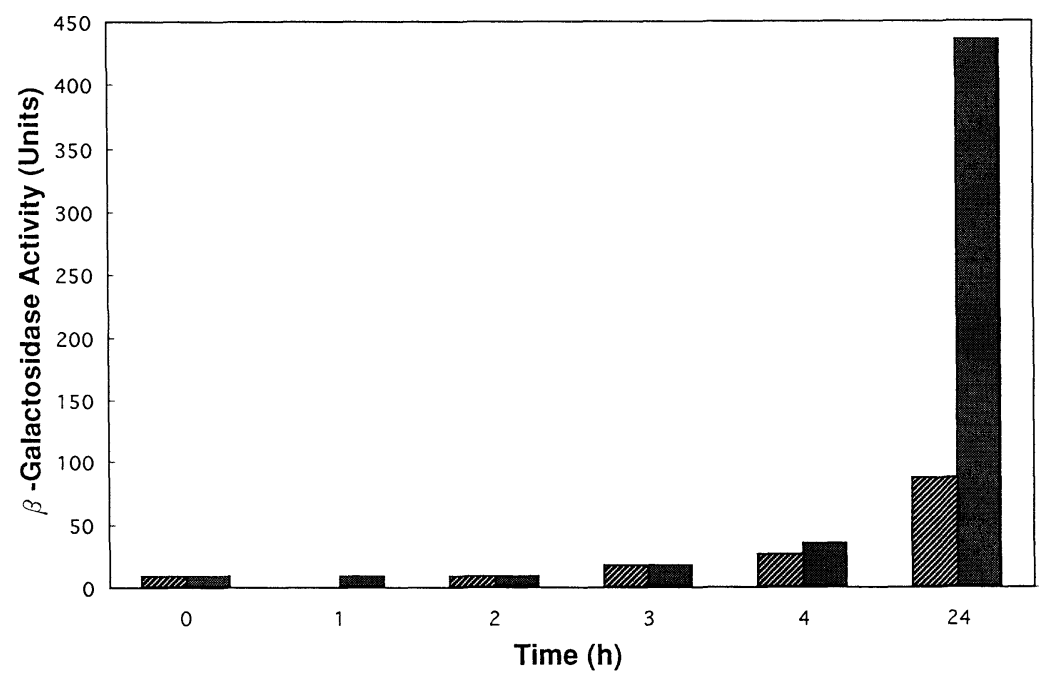

Fig. 3. Growth phase-specific expression of emrK-lacZ'.

E. coli MC4100 containing PMKD1 was cultured for $24 \mathrm{~h}$ in the presence $(\square)$ or absence (שZ) of tetracycline $(2 \mu \mathrm{M})$ as described in Fig. 2, then $\beta$-galactosidase activity was assayed at the indicated times.

tion of tetracycline on cell growth, we continued to measure $\mathrm{OD}_{600}$ for $48 \mathrm{~h}$. After $E$. coli cell growth increased gradually for the first $9 \mathrm{~h}$, it stopped for $10 \mathrm{~h}$ and resumed to increase until $35 \mathrm{~h}$ (Fig. 4B). These results indicate that growth-phase specific emrKY induction is involved in the adaptive mechanism resistant to tetracycline.

Induction after a long incubation in the presence of a subinhibitory concentration of tetracycline was specifically observed, but not in the presence of kanamycin or chloramphenicol (Fig. 5). This experiment showed that the increased expression of emrK- lac $Z^{\prime}$ by chloramphenicol, as shown in Fig. 2, was due to a mechanism which is different from that induced by tetracycline.

Multiple-antibiotic-resistant (Mar) mutants of E. coli express elevated levels of resistance to a wide range of structurally unrelated antibiotics (George and Levy, 1983; Hächler et al., 1991). The alleles that affect the Mar phenotype are located in the marRAB operon (Cohen et al., 1993). The marA gene encodes a positive regulator of antibiotic resistance whose sequence shows strong similarity to those of such transcriptional regulators as SoxS, XyIS and AraC, while marR en- 


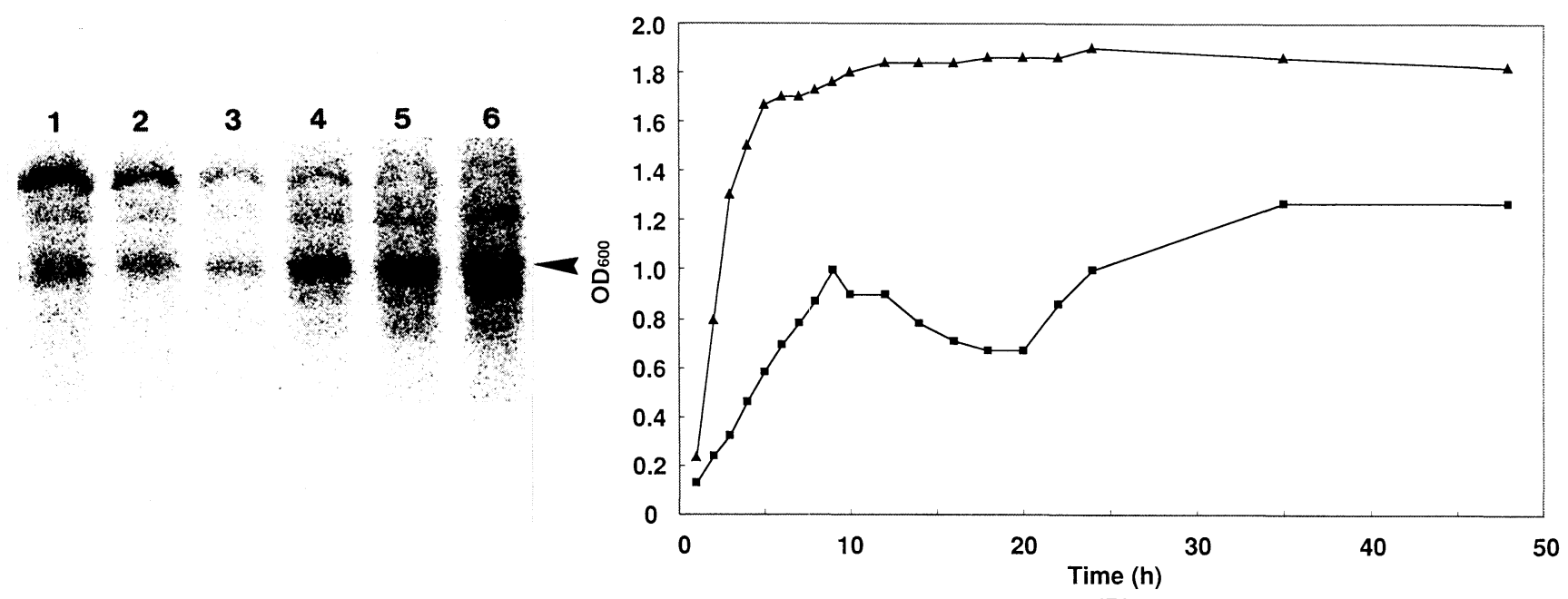

(A)

(B)

Fig. 4. A: Transcriptional regulation of emrKY.

MC4100 containing pMKD1 was cultured overnight. After $5 \mathrm{ml}$ of the overnight culture was added to $500 \mathrm{ml}$ of $\mathrm{L}$ broth in the presence of tetracycline $(2 \mu \mathrm{M})$ and cultured at $37^{\circ} \mathrm{C}$, a $20 \mathrm{ml}$ culture was sampled at $10 \mathrm{~h}$ (lane 1), $12 \mathrm{~h} \mathrm{(lane} 2$ ), $14 \mathrm{~h}$ (lane 3 ), $16 \mathrm{~h}$ (lane 4), $20 \mathrm{~h}$ (lane 5), and $22 \mathrm{~h}$ (lane 6), and total RNA was prepared as described previously (Aiba et al., 1981). Eighty micrograms of total RNA and the probe described in MATERIALS AND METHODS were used for S1 nuclease protection assay (Aiba et al., 1981). The arrow shows the band (198-bp) protected against S1 nuclease.

B: Effect of a subinhibitory concentration of tetracycline on growth.

After MC4100 containing pMKD1 was cultured in the presence $(\boldsymbol{\square})$ or absence $(\mathbf{\Lambda})$ of tetracycline $(2 \mu \mathrm{M})$ as described in MATERIALS AND METHODS, $O D_{600}$ was measured at the indicated times.

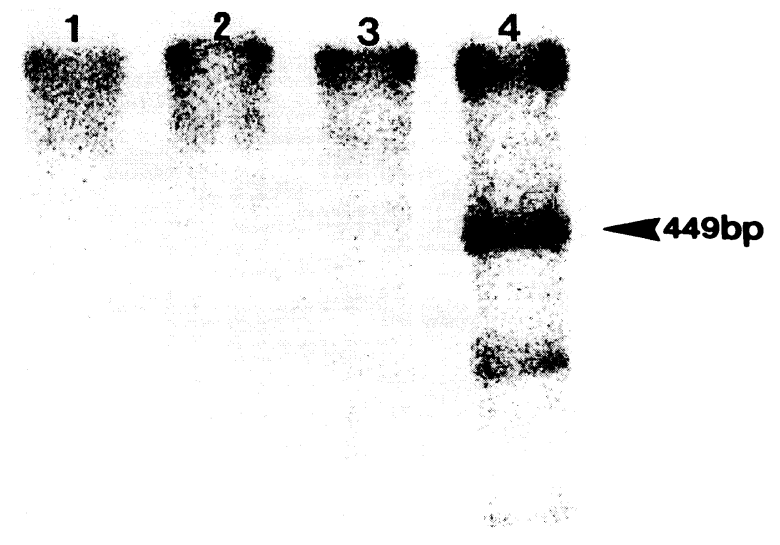

Fig. 5. Effect of drugs on the transcriptional regulation of emrKY.

The probe was prepared as described in MATERIALS AND METHODS. After MC4100 containing pMKD1 was cultured for $24 \mathrm{~h}$ at $37^{\circ} \mathrm{C}$ in the presence of chloramphenicol $(4.6 \mu \mathrm{m}$, lane 2), kanamycin $(10 \mu \mathrm{M}$, lane 3$)$ or tetracycline $(2 \mu \mathrm{M}$, lane 4$)$, and in the absence of drugs (lane 1), total RNA was prepared as described in MATERIALS AND METHODS. This RNA and the probe were used for S1 nuclease assay. The arrow shows the band (449-bp) protected against $\mathrm{S} 1$ nuclease, which corresponds to the transcript as shown in Fig. 4A.

codes a repressor of the marRAB operon (Cohen et al., 1993). The function of marB is not known.

In this study, we have investigated how the Mar system is involved in emrKY gene expression. In a marR mutant (JHC1069), emrK-lacZ' was increased (Fig.
6), but it was decreased in $\mathrm{JHC1096}$, the mutant defective in marRAB (data not shown). The transcription of $a c r A B$ was also elevated in several marR mutants (Ma et al., 1995) and Okusu et al. (1996) showed that marR1 mutation increased the resistance level, but not in the absence of the AcrAB efflux system. These results suggest that emrKY and acrAB gene expression are controlled by the Mar system.

Seoane and Levy identified four mar locus-regulated $(\mathrm{m} / \mathrm{r})$ genes, which were located at 14, 31.5, 51.6 and $77 \mathrm{~min}$ on the $E$. coli chromosome (Seoane and Levy, 1995). The gene at $77 \mathrm{~min}$ was identified as lipoprotein slp (Seoane and Levy, 1995). The other three have not been sufficiently characterized. From DNA sequences, these genes are obviously not identical to emrKY.

Martin et al. showed that salicylate appears to induce the mar operon by binding to MarR and inhibiting complex formation, while tetracycline and chloramphenicol, which neither bind MarR nor inhibit complex formation, must induce by an indirect mechanism (Martin and Rosner, 1995). In MC8301 (Utsumi et al., 1993) (MC4100, rpoS::Tn 10), emrK expression was decreased by tetracycline, but not by chloramphenicol or salicylate (data not shown). These results suggest that emrKY gene expression is controlled by both RpoS and the Mar system, which is different from the mechanism for chloramphenicol and salicylate.

emrKY from pKT06 was cloned into pUC19 to con- 


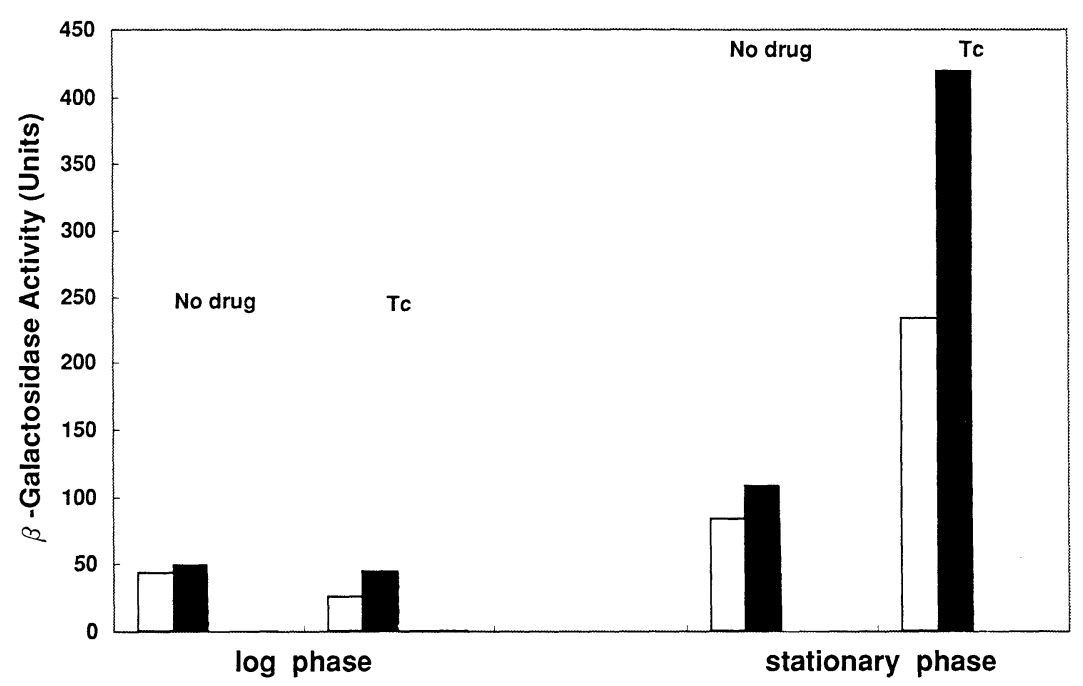

Fig. 6. Involvement of MarR in emrK-lacZ' expression.

E. coli GC4468 $\left(\operatorname{mar}^{+}\right)(\square)$ and JHC1069 $(\operatorname{mar} R)(\square)$ containing pMKD1 were cultured to $0.4 \mathrm{OD}_{600}$ and for $24 \mathrm{~h}$ in the presence or absence of tetracycline $(1 \mu \mathrm{g} / \mathrm{ml})$ as described in MATERIALS AND METHODS, and then $\beta$-galactosidase activity was assayed.

struct pKT03 (Table 1). HN971 (acrA1 and emrB::kan) (listed as HN791, Thanassi et al., 1997) containing pKT03 or pUC19 was incubated for $24 \mathrm{~h}$ in the presence of tetracycline to measure their minimal inhibitory concentrations (MIC). The MICs of HN971 containing pKT03 and pUC19 were $2 \mu \mathrm{M}(1 \mu \mathrm{g} / \mathrm{ml})$ and $0.5 \mu \mathrm{M}(0.25 \mu \mathrm{g} / \mathrm{ml})$, respectively. These results suggest that EmrKY worked as the efflux pump of tetracycline.

The cloned emrY gene belongs to a superfamily of membrane transporters, the major facilitator superfamily (MFS). Although many members of the MFS are involved in solute import, we believe that emrY is involved in the efflux of solute(s) because of two reasons: (a) EmrY is predicted to contain 14 transmembrane segments (TMS), and all of the known 14 TMS members of MFS are exporters of substrates (Paulsen et al., 1996); and (b) EmrY contains some signature sequences found only in drug/proton antiporter members of the MFS, such as the G-X-hy-hy-G-P-X-I-G-G (where hy indicates a hydrophobic residue) (Paulsen et al., 1996), which starts from ala154 in EmrY (A-P-IC-G-P-I-L-G-G). These observations do not necessarily indicate that EmrY is an MDR transporter, because these two features are also found in single-drug efflux proteins of the MFS family (Paulsen et al., 1996). However, the sequence of EmrY is more closely related to a known MDR transporter, EmrB, than to any other single-drug efflux protein (Paulsen et al., 1996), and this seems to suggest that EmrY also functions as a multidrug efflux transporter. The identity of the real substrates of the EmrKY system, however, is not yet clear.

We thank Dr. J. F. Rosner for providing E. coli JHC1096 and Drs. E. Hidalgo and B. Demple for providing E. coli GC4468 and JHC1069. We thank M. Taniguchi, K. Kawamoto, S. Nakade and C. Nishizaka for performing the DNA sequence analyses. We are also grateful to Dr. H. Nikaido for providing E. coli HN971, helpful discussion, and critical reading. This work was supported by grants from the Environmental Science Research Institute, Kinki University, and the Ministry of Education, Science, and Culture of Japan.

\section{References}

Aiba, H., Adhya, S., and deCrombrugghe, B. (1981) Evidence for two functional gal promoters in intact Escherichia coli cells. J. Biol. Chem., 256, 11905-11910.

Casadaban, M. J., Chou, J., and Cohen, S. N. (1980) In vitro gene fusions that join an enzymatically active $\beta$-galactosidase segment to amino-terminal fragments of exogenous proteins: Escherichia coli plasmid vectors for the detection and cloning of translational initiation signals. J. Bacteriol., 143, 971-980.

Cohen, S. P., Hächler, H., and Levy, S. B. (1993) Genetic and functional analysis of the multiple antibiotic resistance (mar) locus in Escherichia coli. J. Bacteriol., 175, 1484-1492.

Davies, J. (1994) Inactivation of antibiotics and the dissemination of resistance genes. Science, 264, 375-382.

George, A. M. (1996) Multidrug resistance in enteric and other gram-negative bacteria. FEMS Microbiol. Lett., 139, 1-10.

George, A. M. and Levy, S. B. (1983) Gene in the major cotransduction gap of the Escherichia coli K-12 linkage map required for the expression of chromosomal resistance and other antibiotics. J. Bacteriol., 155, 541-548.

Greenberg, J. T., Chou, J. H., Monach, P., and Demple, B. (1991) Activation of oxidative stress genes by mutations at the soxQ/cfxB/marA locus of Escherichia coli. J. Bacteriol., 173, 4433-4439.

Hächler, H., Cohen, S. P., and Levy, S. B. (1991) marA, a regulated locus which controls expression of chromosomal multiple an- 
tibiotic resistance in Escherichia coli. J. Bacteriol., 173, $5532-5538$.

Kohara, Y., Akiyama, K., and Isono, K. (1987) The physical map of new strategy for rapid analysis and sorting of a large genome library. Cell, 50, 495-508.

Lewis, K. (1994) Multidrug resistance pumps in bacteria: Variations on a theme. Trends Biochem. Sci., 19, 119-123.

Lomovskaya, O. and Lewis, K. (1992) emr, an Escherichia coli locus for multidrug resistance. Proc. Natl. Acad. Sci. U.S.A., 89 8938-8942.

Lomovskaya, O., Lewis, K., and Matin, A. (1995) EmrR is a negative regulator of the Escherichia coli multidrug resistance pump EmrAB. J. Bacteriol., 177, 2328-2334.

Ma, D., Cook, D. N., Albert, M., Pon, N. G., Nikaido, H., and Hearst, J. E. (1995) Genes acrA and $a c r B$ encode a stress-induced efflux system of Escherichia coli. Mol. Microbiol., 16, 45-55.

Martin, R. G. and Rosner, J. L. (1995) Binding of purified multiple antibiotic-resistance repressor protein (MarR) to mar operator sequences. Proc. Natl. Acad. Sci. U.S.A., 92, 5456-5460.

Miller, J. H. (1972) Experiments in Molecular Genetics. Cold Spring Harbor Laboratory Press, Cold Spring Harbor, NY, pp. 352-355.

Nikaido, H. (1996) Multidrug efflux pumps of gram-negative bacteria. J. Bacteriol., 178, 5853-5859.

Okusu, H., Ma, D., and Nikaido, H. (1996) AcrAB efflux pump plays a major role in the antibiotic resistance phenotype of Escherichia coli multiple-antibiotic-resistance (Mar) mutants. J.
Bacteriol., 178, 306-308.

Paulsen, I. T., Brown, M. H., and Skurray, R. A. (1996) Proton-dependent multidrug efflux systems. Microbiol. Rev., 60, $575-608$.

Seoane, A. S. and Levy, S. B. (1995) Identification of new genes regulated by the marRAB operon in Escherichia coli. J. Bacteriol., 177, 530-535.

Silhavy, T. J., Berman, M. L., and Enquist, L. W. (1984) Experiments with gene fusions. Cold Spring Harbor Laboratory Press, Cold Spring Harbor, NY.

Thanassi, D. G., Cheng, L. W., and Nikaido, H. (1997) Active efflux of bile salts by Escherichia coli. J. Bacteriol., 179, 2512-2518.

Utsumi, R., Katayama, S., Taniguchi, M., Horie, T., Ikeda, M., Igaki, S., Nakagawa, H., Miwa, A., Tanabe, H., and Noda, M. (1994) Newly identified genes involved in the signal transduction of Escherichia coli K-12. Gene, 140, 73-77.

Utsumi, R., Kusafuka, S., Nakayama, T., Tanaka, K., Takayanagi, Y., Takahashi, H., Noda, M., and Kawamukai, M. (1993) Stationary phase-specific expression of the fic gene in Escherichia coli K12 is controlled by the rpoS gene product $\sigma^{38}$. FEMS Microbiol. Lett., 113, 273-278.

Utsumi, R., Yamasaki, K., Furue, M., Sasai, K., Katoh, A., Kawamoto, K., Yoshioka, S., and Tanabe, H. (1996) Inducible mechanism of drug resistances by the two component system, EvgS and EvgA. Nucleic Acids Symposium Series, No. 35, 309-310. 